\title{
Theory of Planned Behavior and Social Cognitive Theory on the Effect of the Community Health Center Tertiary Preventive Behavior among Patients with Type 2 Diabetes Mellitus: A Multilevel Analysis
}

\author{
Yudi Andriyaningtiyas'), Didik Gunawan Tamtomo'), Bhisma Murti1) \\ 1)Masters Program in Public Health, Universitas Sebelas Maret \\ 2)Department of Public Health, Faculty of Medicine, Universitas Sebelas Maret
}

\section{ABSTRACT}

Background: Type 2 diabetes mellitus (DM) accounts for $90 \%$ to $95 \%$ of all diabetes cases. Complications of type 2 diabetes increase the risk of death for sufferers. Complications and deaths from type 2 diabetes can be prevented by changes in behavior. This study aimed to determine the effect of health centers and other factors on the prevention of tertiary diabetes type 2 , using the theory of planned behavior and social cognitive theory.

Subjects and Method: This was an analytic observational study with cross sectional design, conducted at 25 community health centers, in Bantul Regency, Yogyakarta, Indonesia. A sample of 200 type $2 \mathrm{DM}$ patients was selected by exhaustive sampling. The dependent variable was type 2 DM tertiary prevention. The independent variables at level 1 are intention, attitude, subjective norm, perceived behavior control/ self-efficacy, experience, modelling, self-regulation, and outcome expectation. Community health center was an independent variable at level 2. The data were collected by questionnaire and analyzed by a multilevel multiple linear regression.

Results: Tertiary preventive behavior in type 2 $\mathrm{DM}$ patients increased with strong intention $(\mathrm{b}=$ 1.19; $95 \% \mathrm{CI}=0.62$ to 1.76 ; $\mathrm{p}<0.001$ ), positive attitude $(\mathrm{b}=1.19 ; 95 \% \mathrm{CI}=0.58$ to $1.80 ; \mathrm{p}$ $<0.001$ ), supportive subjective norm $(b=0.79$;
95\% CI= 0.12 to $1.45 ; \mathrm{p}=0.019)$, perceived behavior control $(b=1.16 ; 95 \% \mathrm{CI}=0.60$ to $1.72 ; \mathrm{p}$ $<0.001)$, abundant experience $(\mathrm{b}=0.65$; $95 \% \mathrm{CI}=$ 0.62 to $1.25 ; \mathrm{p}<0.001)$, strong modelling ( $\mathrm{b}=$ $1.07 ; 95 \% \mathrm{CI}=0.53$ to $1.67 ; \mathrm{p}=0.030$ ), strong self-regulation $(b=0.87 ; 95 \% \mathrm{CI}=0.34$ to 1.40 ; $\mathrm{p}=0.001)$, and positive outcome expectation $(\mathrm{b}=$ $0.82 ; 95 \% \mathrm{CI}=0.25$ to $1.38 ; \mathrm{p}=0.004)$. Community health center had contextual effect on the tertiary preventive behavior in type $2 \mathrm{DM}$ patients with ICC $=19.18 \%$.

Conclusion: Tertiary preventive behavior in type $2 \mathrm{DM}$ patients increases with strong intention, positive attitude, supportive subjective norm, perceived behavior control, abundant experience, strong modelling, strong self-regulation, and positive outcome expectation. Community health center has contextual effect on the tertiary preventive behavior in type $2 \mathrm{DM}$ patients.

Keywords: tertiary prevention behavior, type 2 diabetes, TBP, SCT, multilevel analysis.

\section{Correspondence:}

Yudi Andriyaningtiyas. Masters Program in Public Health, Universitas Sebelas Maret, Jl. Ir. Sutami No. 36A, Surakarta. Email: yudi.andriyaningtiyas@gmail.com. Mobile: +6281392704899

Cite this as:

Andriyaningtiyas Y, Tamtomo DG, Murti B (2020). Theory of Planned Behavior and Social Cognitive Theory on the Effect of the Community Health Center Tertiary Preventive Behavior among Patients with Type 2 Diabetes Mellitus: A Multilevel Analysis. J Health Promote Behav. 5(1): 59-71. https://doi.org/10.26911/thejhpb.2020.05.01 .08

cc) (†) Journal of Health Promotion and Behavior is licensed under a Creative Commons Attribution-Non Commercial-Share Alike 4.0 International License.

BACKGROUND

The prevalence of diabetes globally increased by approximately $48 \%, 425$ million in 2017 to
629 million in 2045 (IDF, 2017). Nearly half of the 4 million people die of diabetes under the age of 60 , and half of diabetics do not 
know that they have diabetes (IDF, 2017).

The 8th edition of the International Diabetes Federation (IDF) Atlas 2017 reports that in the western Pacific region including Indonesia, the prevalence of diabetes has increased by approximately $15 \%$ from 2017 to 2045 with a total of 159 million to 183 million, with one in three adults live with diabetes, and there are one in three cases of death from diabetes.

Indonesia is the sixth ranked country in the world after China, India, the United States, Brazil and Mexico with the number of diabetics aged 20 to 79 years around 10.3 million people, and is predicted to increase to 16.7 million by 2045 , with an estimated number of deaths due to diabetes at age 20 to 70 years are 114,069 people (IDF, 2017). World Health Organization (WHO) estimates that the number of diabetics in Indonesia will increase to $21,257,000$ by 2030 . Indonesia will be the second highest prevalence country in Southeast Asia (WHO, 2017).

The prevalence of diabetics in Indonesia based on the diagnosis of doctors in the population aged $\geq 15$ years has increased, namely $1.5 \%$ in 2013 to $2.0 \%$ in 2018 (Riskesdas, 2018). The prevalence of diabetics in Yogyakarta Special Region (DIY) is higher than the national average, which is $3.1 \%$ in 2018 , the third highest after DKI Jakarta and East Kalimantan (Riskesdas, 2018). Bantul Regency has the second highest prevalence of diabetes based on a doctor's diagnosis in the population aged $\geq 15$ years which is $3.28 \%$ (Riskesdas, 2018).

Type 2 diabetes accounts for $90 \%$ to $95 \%$ of all diabetes cases (CDC, 2017). Type 2 diabetes is the main cause of early death, so it is necessary to carry out tertiary prevention, namely prevention of complications, prevention of further disability and improving quality of life (Perkeni, 2015).

Bekele's study (2019) shows the burden of diabetes and complications due to diabetes increase in Ethiopia, is associated with increasing disease duration, lower socioeconomic levels, the presence of other complications, and aging.

Diabetes complications can be prevented if managed properly, by making changes in lifestyle, healthy eating, exercise and other physical activities. Healthy behavior is proven to have a positive effect in the prevention and treatment of diabetes (Asif, 2014). Complications of type 2 diabetes can be prevented by modifying lifestyle by increasing physical activity, reducing sitting time, stopping smoking, maintaining body mass index and controlling hypertension, blood glucose and lipids (Alramadan et al., 2019).

Health behaviors carried out by individuals depend on assumed intentions. Intention becomes an antecedent (the forerunner) directly from behavior (Ajzen, 2002). Intention is based on attitudes towards behavior, subjective norms, and perceived behavior control in accordance with Theory of Planned Behavior (TPB).

Banerjee (2019) proves the intention of behavior of healthy Singaporean lifestyle is positively related to attitudes, subjective nor$\mathrm{ms}$, descriptive norms and behavioral control, in addition to determinants of interpersonal communication and mass media.

Behavioral control in TPB originates from the theory of self-efficacy proposed by Bandura from Social Cognitive Theory (SCT). Reciprocal determinism is a central concept in SCT, that behavior is the result of influences generated from within and external influences in the form of environmental factors (Bandura 1986).

Behavioral prevention of type 2 diabetes complications needs to be managed appropriately, including health service facilities. Community health service (Puskesmas) as service provider facilities are expected to be able to spearhead the management of type 2 diabetes and provide services according to 
WHO standards to prevent physical dysfunction and fatal diseases (Ningrum et al., 2017; Amelia, 2018).

This study aimed to determine the effect of health centers and other factors on the prevention of tertiary diabetes type 2 , using the theory of planned behavior and social cognitive theory.

\section{SUBJECTS AND METHOD}

\section{Study Design}

This was an analytic observational study with a cross sectional approach. The study was conducted at 25 Puskesmas in Bantul, Special Region of Yogyakarta, Indonesia, from December 2019 to January 2020.

\section{Population and Sample}

The target population in this study was type 2 diabetes patients. A sample of 200 type $2 \mathrm{DM}$ patients was by using exhaustive sampling.

\section{Study Variables}

The dependent variable was type 2 DM tertiary preventive behavior. The independent variables at level 1 were intention, attitude, subjective norm, perceived behavior control/ self-efficacy, experience, modeling, self-regulation, and outcome expectation. The independent variable at level 2 was puskesmas.

4. Operational Definition of Variables Tertiary prevention of type 2 diabetes was an effort made to prevent complications, prevent complications, prevent disability, and death in patients with type $2 \mathrm{DM}$. The data were measured by questionnaire. The measurement scale was continous, but it was transformed into dichotomous, coded $\mathrm{O}=$ unhealthy; $1=$ healthy.

Intention was the tendency, plan or conscious decision making for tertiary prevention behavior. The data were measured by questionnaire. The measurement scale was continous, but it was transformed into dichotomous, coded $\mathrm{o}=$ weak (score $<11), 1=$ strong (score $\geq 11$ ).

Attitude was the response or judgment to carry out tertiary prevention behavior. The data were measured by questionnaire. The measurement scale was continous, but it was transformed into dichotomous, coded $\mathrm{O}=$ negative (score $<9$ ), $1=$ positive ( score $\geq 9$ ).

Subjective norm was perceptions about rules that exist in the social environment of family members, peers, health workers who have an influence on patient decisions in conducting tertiary prevention behavior. The data were measured by questionnaire. The measurement scale was continous, but it was transformed into dichotomous, coded $\mathrm{o}=$ not supporting (score <11), $1=$ supporting (score $\geq 11$ ).

Perceived behavior control/ self-efficacy was self-beliefs that type 2 diabetes patients are capable of performing tertiary prevention behaviors. The data were measured by questionnaire. The measurement scale was continous, but it was transformed into dichotomous, coded $\mathrm{o}=$ weak (score $<12), 1=$ strong (score $\geq 12$ ).

Experience was everything that is possessed (both knowledge and skills) to carry out tertiary prevention behavior during type 2 diabetes. The data were measured by questionnaire. The measurement scale was continous, but it was transformed into dichotomous, coded $\mathrm{O}=$ few (score <9), $1=$ many (score $\geq 9$ ).

Modeling was the observation of behavior to the model (other people, television, mass media, instructions, etc.), and then adopt the observed behavior according to the considerations of diabetics. The data were measured by questionnaire. The measurement scale was continous, but it was transformed into dichotomous, coded $\mathrm{o}=$ weak (score $<7$ ), $1=$ strong (score $\geq 7$ ).

Self-regulation was the ability to use oneself to identify and assess behavior before adopting a behavior. The data were measured by questionnaire. The measurement scale was continous, but it was transformed into 
dichotomous, coded $\mathrm{O}=$ weak $($ score $<9), 1=$ strong (score $\geq 9$ ).

Outcome expectation was the values desired by individuals for a behavioral outcome. The data were measured by questionnaire. The measurement scale was continous, but it was transformed into dichotomous, coded $\mathrm{O}=$ negative (score $<7$ ), $1=$ positive (score $\geq 7$ ).

Puskesmas was one of the first-level health facilities that provide type $2 \mathrm{DM}$ service.

\section{Data Analysis}

Univariate analysis used to describe each dependent and independent variable, the data is classified according to data types. Bivariate analysis was performed to determine the correlation of variables, the mean differrence of the two groups tested using the $t$ test. Multivariate analysis was performed using linear regression through a multilevel analysis approach.

\section{Research Ethics}

Research ethics includes consent sheets, anonymity, confidentiality, and ethical eligibility. The ethical eligibility in this study came from the Health Research Ethics Committee at Dr. Moewardi Hospital number: 1,282 / XII / HREC / 2019.

\section{RESULTS}

\section{Univariate Analysis}

Table 1 shows a description of the sample characteristics. The average value of intention is 11.34, with a minimum value of 5 and a maximum value of 14 . The average attitude value is 9.34, with a minimum value of 4 and a maximum value of 14 . The average subjective norm value is 10.91 , with a minimum value of 5 and a maximum value of 14 .

The average value of perceived behavioral control is 12.02, with a minimum value of 3 and a maximum value of 20 . The average value of experience is 8.52 , with a minimum value of 2 and a maximum value of 12 . The average value of modeling is 6.49 , with a minimum value of $o$ and a maximum value of 10.

The average value of self-regulation is 8.56 , with a minimum value of 2 and a maximum value of 10 . The average value of expected outcomes is 7.48 , with a minimum value of 3 and a maximum of 10. Average value of preventive behavior is 16.74 , with a minimum value of 5 and a maximum value 20.

Table 2 shows that type 2 diabetes patients have more strong intention (61.50\%) than weak $(38.50 \%)$, most are positive (59.50\%) than negative (40.50\%), most have subjective norms of support (54.50\%) than non-supports (54.50\%) 45.50\%).

Most patients with type 2 diabetes have strong perceived behavior control (55.50\%) rather than weak (44.50\%), most have less experience (53\%) than many (47\%), most have strong modeling (69\%) than weak (31\%), most had positive outcome expectation $(58.50 \%)$ than negative $(41.50 \%)$, and most had healthy prevention behaviors (62\%) rather than unhealthy (38\%).

Table 1. Sample characteristics (continuous data)

\begin{tabular}{llllcc}
\hline \multicolumn{1}{c}{ Variable } & (n) & Mean & SD & Min. & Max. \\
\hline Intention & 200 & 11.34 & 2.70 & 5 & 14 \\
Attitude & 200 & 9.34 & 2.57 & 4 & 14 \\
Subjective norm & 200 & 10.91 & 2.74 & 5 & 14 \\
Behavioral control perception & 200 & 12.02 & 4.05 & 3 & 20 \\
Experience & 200 & 8.52 & 2.75 & 2 & 12 \\
Modeling & 200 & 6.49 & 2.56 & 0 & 10 \\
Self-regulation & 200 & 8.56 & 1.65 & 2 & 10 \\
Expectations of results & 200 & 7.48 & 2.08 & 3 & 10 \\
Tertiary preventive behavior & 200 & 16.74 & 3.07 & 5 & 20 \\
\hline
\end{tabular}


Andriyaningtiyas et al./ Tertiary Preventive Behavior in Type 2 DM Patients

Table 2. Sample characteristics (dichotomous data)

\begin{tabular}{|c|c|c|c|}
\hline Characteristics & Criteria & $\mathbf{n}$ & Persentage (\%) \\
\hline \multirow[t]{2}{*}{ Intention } & Weak $(<11)$ & 77 & 38.50 \\
\hline & Strong $(\geq 11)$ & 123 & 61.50 \\
\hline \multirow[t]{2}{*}{ Attitude } & Negative $(<9)$ & 81 & 40.50 \\
\hline & Positive $(\geq 9)$ & 119 & 59.50 \\
\hline \multirow[t]{2}{*}{ Subjective Norm } & Not supporting $(<11)$ & 91 & $45 \cdot 50$ \\
\hline & Supporting $(\geq 11)$ & 109 & 54.50 \\
\hline \multirow[t]{2}{*}{ Perceived behavior control } & Weak $(<12)$ & 89 & 44.50 \\
\hline & Strong $(\geq 12)$ & 111 & 55.50 \\
\hline \multirow[t]{2}{*}{ Experience } & Little $(<9)$ & 106 & 53.00 \\
\hline & Many $(\geq 9)$ & 95 & 47.00 \\
\hline \multirow[t]{2}{*}{ Modeling } & Weak $(<7)$ & 62 & 31.00 \\
\hline & Strong $(\geq 7)$ & 138 & 69.00 \\
\hline \multirow[t]{2}{*}{ Self-Regulation } & Weak $(<9)$ & 97 & 48.50 \\
\hline & Strong $(\geq 9)$ & 103 & 51.50 \\
\hline \multirow[t]{2}{*}{ Expectations of results } & Negative $(<7)$ & 83 & 41.50 \\
\hline & Positive $(\geq 7)$ & 117 & 58.50 \\
\hline \multirow[t]{2}{*}{ Tertiary preventive behavior } & Unhealthy & 76 & 38.00 \\
\hline & Healthy & 124 & 62.00 \\
\hline
\end{tabular}

\section{Bivariate Analysis}

Bivariate analysis was used to examine the influence between independent variables (intentions, attitudes, subjective norms, perceptions of behavioral control, experience, modeling, self-regulation, and outcome expectations), dependent variables (type 2 diabetes tertiary prevention behavior).

Table 3 shows type 2 diabetes patients with strong intention toward preventive behavior ( mean $=18.02)$ had higher tertiary prevention behavior than those with weak intention $($ mean $=14.68)$, and it was statistically significant $(\mathrm{p}<0.001)$.

Type 2 DM patients with positive attitude toward preventive behavior (mean= 18.24) had higher tertiary preventive behavior than those with negative attitude (mean $=14.53$ ), and it was statistically significant $(\mathrm{p}<0.001)$.

Type 2 DM patients with supportive subjective norm (mean $=18.40$ ) had higher tertiary preventive behavior than those with unsupportive subjective norm (mean=14.74), and it was statistically significant $(\mathrm{p}<0.001)$.

Type 2 DM patients with strong per- ceived behavior control $($ mean $=18.27)$ had higher tertiary preventive behavior than those with weak perceived behavior control (mean $=14.82$ ), and it was statistically significant ( $\mathrm{p}<0.001)$.

Type 2 DM patients with a lot of experience $($ mean $=18.52)$ had higher tertiary preventive behavior than those with less experience $($ mean $=15.15)$, and it was statistically significant ( $\mathrm{p}<0.001)$.

Type 2 DM patients with strong modeling (mean $=17.57$ ) had higher tertiary preventive behavior than those with weak modeling (mean=14.87), and it was statistically significant $(\mathrm{p}<0.001)$.

Type 2 DM patients with strong selfregulation (mean $=18.02$ ) had higher tertiary preventive behavior than those with weak self-regulation $($ mean $=15.37)$, and it was statistically significant $(\mathrm{p}<0.001)$.

Type 2 DM patients with positive outcome expectation (mean $=18.01$ ) had higher tertiary preventive behavior than those with negative outcome expectation ( mean=14.94), and it was statistically significant ( $\mathrm{p}<0.001)$. 
Andriyaningtiyas et al./ Tertiary Preventive Behavior in Type 2 DM Patients

Table 3. Bivariate analysis of differences in mean scores of type 2 diabetes 2 tertiary prevention behavior between the two groups (analysis by $t$ test)

\begin{tabular}{llccc}
\hline Independent Variable & & n & Mean & p \\
\hline Intention & Weak & 77 & 14.68 & \\
Attitude & Strong & 123 & 18.02 & $<0.001$ \\
Subjective norm & Negative & 81 & 14.53 & \\
& Positive & 119 & 18.24 & $<0.001$ \\
Perceived behavior control & Not supporting & 91 & 14.74 & \\
& Supporting & 109 & 18.40 & $<0.001$ \\
Experience & Weak & 89 & 14.82 & \\
& Strong & 111 & 18.27 & $<0.001$ \\
Modeling & Little & 106 & 15.15 & \\
& Much & 94 & 18.52 & $<0.001$ \\
Self-Regulation & Weak & 62 & 14.87 & \\
& Strong & 138 & 17.57 & $<0.001$ \\
Outcome expectation & Weak & 97 & 15.37 & \\
& Strong & 103 & 18.02 & $<0.001$ \\
& Negative & 83 & 14.94 & \\
& Posittve & 117 & 18.01 & $<0.001$ \\
\hline
\end{tabular}

\section{Multilevel Analysis}

Table 4 shows that there was a positive effect of intention on tertiary prevention behavior. Diabetic patients with strong intention had logodd to healthy tertiary behavior prevention 1.19 units higher than than those with weak intention $(b=1.19 ; 95 \% \mathrm{CI}=0.62$ to 1.76; $\mathrm{p}<0.001)$.

There was a positive effect of attitude on tertiary prevention behavior. Diabetic patients with positive attitude had logodd to healthy tertiary prevention behavior 1.19 units higher than than those with negative attitude $(\mathrm{b}=1.19 ; 95 \% \mathrm{CI}=0.58$ to $1.80 ; \mathrm{p}$ $<0.001)$.

There was a positive effect of subjective norms on tertiary preventive behavior. Diabetic patients with supportive subjective norm had logodd to healthy tertiary prevention behavior 0.79 units higher than those with unsupportive subjective norm $(b=0.79$; $95 \% \mathrm{CI}=0.12$ to $1.45 ; \mathrm{p}=0.019)$.

There was a positive effect of perceived behavioral control on tertiary prevention behavior. Diabetic patients with strong behavioral control perception had logodd to healthy tertiary preventive behavior $\mathbf{1 . 1 6}$ units higher than those with weak perceived behavior control $(b=1.16$; $95 \% \mathrm{CI}=0.60$ to 1.72; $\mathrm{p}<0.001$ ).

There was a positive effect of experience on tertiary prevention behavior. Diabetic patients with extensive experience had logodd to healthy tertiary preventive behavior o.65 units higher than those with less experience $(b=0.65 ; 95 \% \mathrm{CI}=0.62$ to $1.25 ; \mathrm{p}<$ o.001).

There was a positive effect of modeling on tertiary preventive behavior. Diabetic patients with strong modeling had logodd to healthy tertiary preventive behavior 1.07 units higher than those with weak modeling $(b=1.07 ; 95 \% \mathrm{CI}=0.53$ to $1.67 ; \mathrm{p}=0.030$ ).

There was a positive effect of self-regulation on tertiary prevention behavior. Diabetic patients with strong self-regulation had logodd to healthy behavior preventive behavior 0.87 units higher than those with weak self-regulation $(b=0.87 ; 95 \% \mathrm{CI}=0.34$ to $1.40 ; \mathrm{p}=0.001)$.

There was a positive effect on outcome expectations on tertiary prevention behavior. Diabetic patients with positive outcome expectacy had logodd to healthy tertiary pre- 
ventive behavior 0.82 units higher than those with negative outcome expectation $(b=0.82$; $95 \% \mathrm{CI}=0.25$ to $1.38 ; \mathrm{p}=0.004$ ).

ICC value $=19.18 \%$, meaning that there is a contextual influence of puskesmas on the type 2 diabetes prevention tertiary behavior. The indicator shows that as many as $19.18 \%$ of the variation in the type 2 diabetes prevention is determined by variables at the puskes- mas level. This figure is greater than the standard rule of thumb size of $8-10 \%$, so the contextual influence shown from multilevel analysis is very important to note. Table 5 also shows the LR test results vs linear regression $\mathrm{p}<0.001$, this means that the multilevel model is statistically significantly different from the linear regression model.

Table 4. Multilevel multiple linear regression analysis of the contextual effect of puskesmas and other factors on tertiary prevention behavior for type 2 diabetes

\begin{tabular}{|c|c|c|c|c|c|}
\hline \multirow[b]{2}{*}{ Independent Variable } & \multirow{2}{*}{$\begin{array}{l}\text { Coefficient } \\
\text { (b) }\end{array}$} & \multirow[b]{2}{*}{ SE } & \multicolumn{2}{|c|}{$95 \% \mathrm{CI}$} & \multirow[b]{2}{*}{$\mathbf{p}$} \\
\hline & & & $\begin{array}{c}\text { Lower } \\
\text { Limit }\end{array}$ & $\begin{array}{l}\text { Upper } \\
\text { Limit }\end{array}$ & \\
\hline \multicolumn{6}{|l|}{ Fixed Effect } \\
\hline Intention (strong) & 1.19 & 0.29 & 0.62 & 1.76 & $<0.001$ \\
\hline Attitude (positive) & 1.19 & 0.31 & 0.58 & 1.80 & $<0.001$ \\
\hline Subjective Norm (supporting) & 0.79 & 0.34 & 0.12 & 1.45 & 0.019 \\
\hline $\begin{array}{l}\text { Perceived behavior control/self- } \\
\text { efficacy (strong) }\end{array}$ & 1.16 & 0.28 & 0.60 & 1.72 & $<0.001$ \\
\hline Experience (much) & 0.65 & 0.30 & 0.62 & 1.25 & $<0.001$ \\
\hline Modeling (strong) & 1.07 & 0.28 & 0.53 & 1.67 & 0.030 \\
\hline Self-regulation (strong) & 0.87 & 0.27 & 0.34 & 1.40 & 0.001 \\
\hline Outcome expectation (positive) & 0.82 & 0.29 & 0.25 & 1.38 & 0.004 \\
\hline \multicolumn{6}{|l|}{ Random effect } \\
\hline Public health center & 12.24 & 0.31 & 11.62 & 12.86 & \\
\hline $\begin{array}{l}\text { Constanta } \\
\mathrm{n} \text { observation }=200 \\
\mathrm{n} \text { public health center }=25 \\
\text { Log likelihood }=-391.12 \\
\text { LR test vs. linear regression, } \mathrm{p}<0.001 \\
\mathrm{ICC}=19.18 \%\end{array}$ & 0.61 & 0.27 & 0.26 & 1.45 & \\
\hline
\end{tabular}

DISCUSSION

1. The effect of intention on type 2 diabetes tertiary prevention behavior

The results showed that there was a significant influence between intention to prevent type 2 tertiary diabetes behavior. Diabetic patients with strong intention to increase tertiary prevention behavior were 1.19 units compared to those with weak intention.

A study by Ferreira and Pereira (2017) showed that in TPB the realization of behavior is determined in advance by intention. The intention to perform physical activity in diabetic patients is the only predictor of adherence to the physical activity of type 2 diabetes patients. The stronger the intention to carry out physical activity, the more likely it is to conduct behavior. Patient who intend to do physical activity, are more likely to do it effectively.

A study by Bauer et al. (2019) conducted using path analysis shows behavior belief, normative belief, and control belief are prediction of intention to eat healthy food behavior, intention is a strong and significant predictor of food intake behavior in type 2 diabetes patients. Intention is beginners directly before the behavior occurs, therefore the stronger the intention, the more likely the behavior will occur. Damayanti (2018) 
reported that strong intentions affect positively and directly the management of self-care for patients with type 2 diabetes.

\section{The effect of attitude on type 2 dia- betes tertiary prevention behavior}

The results showed a significant difference between attitudes toward the prevention of tertiary diabetes type 2. Diabetic patients with a positive attitude increased tertiary prevention behavior than those with negative attitude.

Attitude is one of the variables that influences intention, attitude toward behavior becomes one of the strong determinants of weak intention to behave. A positive attitude towards behavior will increase the intention to behave and realize the behavior. Conversely, a negative attitude toward behavior will reduce the intention to behave and realize the behavior.

A study by Jannuzzi et al. (2019) show attitude and subjective norm together explain $30 \%$ of the variability in intentions. Intention is determined by subjective attitudes and norms in behavior related to adherence to taking antidiabetic drugs, so it is necessary to include motivational strategies and targeted strategies to strengthen attitude and subjective norm when designing an intervention.

Ferreira and Pereira (2017) reinforced the influence of attitude on behavior through intention. It showed that in addition to perceived behavior control, a positive attitude influences strong intention to perform physical activity, the importance of emphasizing attitude and perceived control about intention to perform physical activity in patients type 2 diabetes.

\section{The effect of subjective norm on type 2 diabetes tertiary prevention behavior}

The results showed there was a significant influence between subjective norm on type 2 diabetes tertiary prevention behavior. Diabetics with subjective norms that support in- creased tertiary prevention behavior were 0.79 units higher than those with unsupportive subjective norm.

Wongrith (2019) mentioned that most patients have subjective norms that support and positive attitudes toward healthy eating behavior, good exercise, and medication adherence, which results in strong perceptions, thus enabling them to have strong intentions to conduct behavior. Subjective norms and perceived control are highly correlated with behavioral intentions and selfcare behavior in patients with type 2 diabetes.

Concern by family members supports strong predictions with behavior control for patients to perform self-care behavior (these variables account for $30 \%$ of the general variants). It is important for health care providers to assess sources of social support and integrate the results of these assessments to ensure patient empowerment during diabetes education (Wongrith, 2019).

Family support and physician trust have a major influence on the acceptance and performance of diabetes self-care management (DSCM) and are very important for further improvement. The influence of subjective norms that support improving behavior includes the prevention of tertiary type 2 diabetes (Wongrith, 2019).

Banerjee and Ho (2019) in applying TPB shows that besides intention and attitude, subjective norm are also proven to positively influence healthy behavior. Subjective norms affect intentions to behave, in addition to attitudes to behavior. Subjective norms describe social pressures or social support felt by individuals when doing or not doing a behavior. Society can oppose or prohibit, or vice versa support, approve or approve of a behavior. Together with attitudes towards behavior, subjective norms affect intention to behave, and subsequently influence a person to realize the behavior. 


\section{The effect of perceived behavior control/ self-efficacy on tertiary type 2 diabetes prevention behavior}

The results showed there was a significant influence between perceived behavior control/ self-efficacy on tertiary prevention behavior for type 2 diabetes. Diabetic patients with strong perceived behavior control increased tertiary prevention behavior 1.16 units than those with weak perceived behavior control.

Perceived behavior control can act as an effect modifier in the relationship between intention and behavior. The impact of intention on behavior can be stronger if the perceived behavior control is strong. A relatively weak intention to behave may be manifested in behavior if the individual has a strong perceived behavior control, which is to see that the behavior is easy to do and has the skills needed to perform the behavior. Conversely, a relatively strong intention to behave may not be realized in a behavior if the individual views the behavior as difficult and does not have the skills needed to perform the behavior.

Seaborn et al. (2016) showed that perceived behavior control is a strong predictor of the possibility of adopting type 2 diabetes preventive behavior. Dilekler et al. (2019) stated the importance of perceived behavior control of adherence to monitoring blood glucose, following a healthy diet, exercising, and taking medication, so perceived behavior control is important when considering interventions for type 2 diabetes patients.

Wongrith (2019) stated that perceived behavior control is the most important factor that predicts the intention and behavior of self-care management, reinforced by Menti et al. (2019) showed self-efficacy in SCT to be most effective for influencing behavioral changes in terms of increasing medication adherence, diet and physical exercise for people with type 2 diabetes when combined with goal setting practices.

\section{The effect of experience on type 2 diabetes tertiary prevention behavior}

The results showed that there was a significant influence between experience on tertiary prevention behavior for type 2 diabetes. Diabetic patients with more experience increased tertiary prevention behavior than those less little experience.

SCT takes into account a person's experiences in the past, which determine whether a behavior will actually be realized. Past experience plays a role in strengthening, shaping expectations and giving hope values that will determine whether a person will start doing or continue to do a certain behavior or not, as well as providing reasons that underlie why the person performs that behavior, this is in accordance with a study from Petosa's and Silfee (2016), that experience can be used in improving self-regulation skills to support adherence to physical activity for type 2 diabetes patients with obesity.

A positive experience of a diabetic can motivate him to behave healthy. Palareti et al. (2016) mentioned that the treatment of a very low-energy diet for 8 weeks in patients with type 2 diabetes with weight loss results, well-controlled blood sugar levels and improved long-term health provided motivation and made the experience that selfcontrol with proper diet became one behavior that must be performed by people with type 2 diabetes.

The experience of suffering from diabetes can be traumatic, this is influenced by the severity of the disease, the level of education, perceived social support, the focus of treatment on the problem and the lack of consideration of patients emotionally or psychologically during treatment. To overcome the trau matic experience, intervention is needed by paying attention to social support, adaptive and emotional coping strategies, based on the experience gained can be positively not trau- 
matic to change the healthy behavior of people with type 2 diabetes (Dirik and Gocek Yorulmaz, 2018).

\section{Effect of modeling on the type 2 dia- betes tertiary prevention behavior}

The results showed there was a significant influence between modeling on the type 2 diabetes tertiary prevention behavior.

One construct in SCT is observational learning, referring to the idea that someone with a chronic illness can observe and learn the behavior of others who live in the same community, and then individuals with chronic illness can reproduce the action. This is often called behavior modeling. If diabetics see a good model of a particular behavior, then it will decide to imitate the behavior (Thojampa and Sarnkhaowkhom, 2019).

Esmaeily et al. (2014) also shows one of the determinants of physical activity in women with type 2 diabetes is modeling, where modeling has an influence on physical activity, but indirectly. Effective modeling (through observation) is a source for building self-efficacy and outcome expectations.

SCT states that when an individual observes a model that performs a behavior and the consequences of that behavior, then the individual will remember the sequence of events and then use that information to guide the new behaviors that he will do. Observing a model can also encourage individuals to perform behaviors that have previously been studied (Bandura, 1986; Boston School of Public Health, 2018).

SCT studies the process of acquiring knowledge or learning that correlates directly with the observation of the model. Effective modeling teaches general rules or strategies for dealing with different situations (Bandura, 1988).

\section{Effect of self-regulation on type 2 diabetes tertiary prevention beha- vior}

The results showed there was a significant in- fluence between self-regulation on type 2 diabetes tertiary prevention behavior. Diabetic patients with strong self-regulation increased tertiary prevention behavior than those with weak self-regulation.

Ghoreishi et al. (2019) showed that selfregulation was a determinant in the self-care of diabetic patients, and was statistically significant $(\mathrm{p}<0.001)$. Nazari et al. (2019) showed self-regulation as a direct predictor of physical activity in female patients with type 2 diabetes.

Castonguay et al. (2018) showed the importance of self-regulation of adherence to behaving in physical activity in patients with type 2 diabetes. Self-regulation of behavior is the process of individuals to use their own thoughts and actions to achieve a goal, in self-regulation a person identifies goals, adopts a strategy, and maintain a strategy for achieving goals. Without self-regulation, individuals are unable to maintain if behavior is not strengthened

\section{The effect of outcome expectations on type 2 diabetes tertiary prevent- ion behavior}

The results showed there was a significant effect between outcome expectation on type 2 diabetes tertiary prevention behavior.

Borhaninejad et al. (2017) showed that outcome expectations are also a strong predictor of correctly and holistically identifying self-care behavior in diabetic patients, thereby helping to manage diabetes and reduce complications.

Ghoreishi et al. (2019) also proved that outcome expectations were also one of the determinants in the self-care of diabetic patients, and were statistically significant ( $p$ $<0.001$ ). Expectations of results have an important role in the development of the inclusion of cognitive explanations for the occurrence of behavior in SCT. Expected outcomes are values given by individuals to the anticipated consequences of a behavior. Expecta- 
tions for positive results will improve behavior, and vice versa expectations of negative outcomes decrease behavior.

\section{Effect of contextual puskesmas on tertiary prevention behavior for type 2 diabetes}

The results showed that $\mathrm{ICC}=19.8 \%$ which means there is a contextual influence of puskesmas on the type 2 diabetes prevention tertiary behavior. Variation of the type 2 diabetes prevention is determined at the individual level and the contextual level of the puskesmas. LR test vs linear regression showed a value of $\mathrm{p}<0.001$, this means that the multilevel model was statistically significantly different from the ordinary linear model.

\section{AUTHOR CONTRIBUTION}

Yudi Andriyaningtiyas as the main researcher developed a conceptual framework, collected data, analyzed data, and wrote papers. Didik Gunawan Tamtomo guided contextually in the discussion. Bhisma Murti guides the preparation of conceptual frameworks, did data analysis, and interpreted the results of data analysis.

\section{CONFLICT OF INTEREST}

There is no conflict of interest in this study.

\section{FUNDING AND SPONSORSHIP}

This study is funded by the Indonesian Ministry of Health's Human Resource Quality Improvement Fund.

\section{ACKNOWLEDGEMENT}

The author thanks the 25 heads of the puskesmas in Bantul Regency, Special Region of Yogyakarta, who gave permission for data collection. Thank you to all parties involved in collecting data in this study.

\section{REFERENCE}

Ajzen I (2002). Perceived behavioral control, self-efficacy, locus of control, and the theory of planned behavior. J ApplSoc
Psychol, 32(4): 665-683. doi: 10.1111/j.1559-1816.2002.tboo236.x.

Alramadan MJ, Magliano DJ, Alhamrani HA, Alramadan AJ, Alameer SM, Amin GM, Alkharras WA, et al(2019). Lifestyle factors and macro and microvascular complications among people with type 2 diabetes in Saudi Arabia. Diabetes Metab Syndr,13(1): 484491. doi: 10.1016/j.dsx.2018.11.007.

Amelia R, Lelo A, Lindarto D, Mutiara E (2018). Quality of life and glycemic profile of type 2 diabetes mellitus patients of Indonesian: A descriptive study. Ictromi, 125(1): 0-5. doi: 10.1088/17$55-1315 / 125 / 1 / 012171$.

Asif M (2014). The prevention and control the type-2 diabetes by changing lifestyle and dietary pattern. JEHP, 3:1-8. doi: 10.4103/2277-9531.127541.

Bandura A (1986). Social foundations of thought and action: a social cognitive theory. Englewood Cliffs, NJ: PrenticeHall.

Bandura A (1988). organizational application of social cognitive theory. Aust $\mathrm{J}$ Manag 13 (2): 275-302. doi:10.1177/031289628801300210 .

Banerjee S, Ho SS (2019). Applying the theoryof planned behavior: Examining how communication, attitudes, social nor$\mathrm{ms}$, and perceived behavioral control relate to healthy lifestyle intention in Singapore. Int J Health Manag, 1-8. doi: 10.1080/20479700.2019.1605687.

Bekele BB (2019). The prevalence of macro and microvascular complications of DM among patients in Ethiopia 1990e2017: Systematic review. Diabetes Metab Syndr, 13(1): 672-677. doi: 10.1016/j.dsx.2018.11.046.

Borhaninejad V, Tahami AN, Yousefzadeh G, Shati M, Iranpour A, Fadayevatan R (2017). Predictors of selfcare among the elderly with diabetes type 2: using so- 
cial cognitive theory. Diabetes and metabolic syndrome: clinical research and reviews. Diabetes Metab Syndr, 11(3): 163-166. doi: 10.1016/j.dsx.2016.08.017.

Boston School of Public Health (2018): The social cognitive theory. Retrieved from http://sphweb.bumc.bu.edu/otlt/MPM odules/SB/BehavioralChangeTheories/BehavioralChangeTheories5.html.

Castonguay A, Miquelon P and Boudreau F. (2018). Self-regulation resources and physical activity participation among adults with type 2 diabetes. HPO, 5(1). doi: 10.1177/2055102917750331.

CDC (2017). National diabetes statistics report 2017, estimates of diabetes and its burden in the United States. Retrieved from https://www.cdc.gov/diabetes/pdfs/data/statistics/national-diabetes-statistics-report.pdf.

Damayanti A, Tamtomo D, Indarto D (2018). Theory of planned behavior implementation on the factors affectting self-care management in type 2 diabetes mellitus patients. JHealth Promot Behav, 3(2): 139-145. doi: 10.26911/thejhpb.2018.03.02.08.

Dilekler I, Dogulu C and Bozo O. (2019). A test of theory of planned behavior in type II diabetes adherence: The leading role of perceived behavioral control. Current Psychology. doi: 10.1007/s12144-019-00309-7.

Dirik G, Gocek YE. (2018). Positive sides of the disease: Posttraumatic growth in adults with type 2 diabetes.Transl Behav Med, 44(1): 1-10. doi: 10.1080/o8964289.2016.1173635.

Esmaeily H, Peyman N, Taghipour A, Khorashadizadeh F, Mahdizadeh $\mathrm{M}$ (2014). A structural equation model to predict the social-cognitive determinants related to physical activity in iranian women with diabetes mellitus. JRHS,
14(4): 296-302.

Ferreira G, Pereira MG (2017). Physical activity: The importance of the extended theory of planned behavior, in type 2 diabetes patients. J Health Psychol, 22(10): 1312-1321. doi: 10.1177/1359105315626787.

Ghoreishi MS, Shahroodi MV, Jafari A, Tehranid H (2019). Self-care behaviors in patients with type 2 diabetes: Education intervention base on social cognitive theory. Diabetes Metab Syndr,13(3): 2049-2056. doi: 10.1016/j.dsx.2019.04.045.

IDF (2017). New IDF clinical practice recommendations for managing type 2 diabetes in primary care. Diabetes Res Clin Pract, 132: 169-170. doi: 10.1016/j.diabres.2017.09.002.

IDF (2017). IDF diabetes atlas, Eighth edition 2017. Brussels: International Diabetes Federation. Retrieved from https://www.idf.org/our-activities/advocacy-awareness/resources-and-tools/134idf-diabetes-atlas-8th-edition.html.

Jannuzzi FF, Cornelio ME, Sao-Joao TM, Gallani MC, Godin G, Rodrigues RCM (2019). Psychosocial determinants of adherence to oral antidiabetic medication among people with type 2 diabetes. J Clin Nurs. doi: 10.1111/jocn.15149.

Menti D, Limbert C, Lyrakos, G (2019). Investigating the effectiveness of theorybased interventions for improving treatment adherence of patients with type 2 Diabetes Mellitus: A systematic review of randomised controlled clinical trials. J Health Soc Sci. doi: 10.19204/2019/nvst9.

Murti B (2018). Teori promosi dan perilaku kesehatan (Promotion theory and health behavior). Colomadu, Karanganyar, Jawa Tengah: Bintang Fajar Offset.

Nazari LN, Javazdzade H, Tahmasebi R, 
Reisi M (2019). Predictors of physical activity-related energy expenditure among overweight and obese middleaged women in south of Iran: An application of social cognitive theory. Obes Med Elsevier, 14: 100078. doi: 10.1016/j.obmed.2019.01.002.

Ningrum VDA, Ikawati Z, Sadewa AH, Ikhsan MR (2018). Glycemic control and prevalence of chronic kidney disease in type 2 diabetes mellitus patients at primary healthcare centers in Yogyakarta Province 2015. IJCP, 6(2): 78-90. doi: 10.15416/ijcp.2017.6.2.78.

Palareti G, Legnanai C, Antonucci E, Erba N, Poli D, Testa S, et al (2016). Comparison between different Dimer cutoff values to assess the individual risk of recurrent venous thromboembolism: Analysis of results obtained in the Dulcis study. Int J Lab Hematol, 38(1): 4249. doi: 10.1111/ijlh.12426.

Perkumpulan Endokrinologi Indonesia (Perkeni) (2015). Konsensus pengelolaan dan pencegahan diabetes melitus tipe 2 di Indonesia 2015 (Consensus on the management and prevention of type 2 diabetes mellitus in Indonesia 2015). Retrieved from https://pbperkeni.or.id/wpcontent/uploads/2019/o1/4.Konsensus Pengelolaan-dan-Pencegahan-Diabetes-melitus-tipe-2-di-Indonesia-PERKENI-2015.pdf.

Petosa RL, Silfee V (2016). Construct validation of a program to increase use of self-regulation for physical activity among overweight and obese adults with type 2 diabetes mellitus. Am J Health Educ, 47(6): 379-384. doi: 10.1080/19325037.2016.1219284

Riset Kesehatan Dasar (Riskesdas) (2018). Badan penelitian dan pengembangan kesehatan kementerian RI (Indonesian Ministry of Health's Health Research and Development Agency). Retrieved from https://www.depkes.go.id/resources/download/info-terkini/hasil-riskesdas-2018.pdf.

Seaborn C, Suther S, Lee T, Kiros GE, Becker A, Campbell E, Robinson JC (2016). Utilizing genomics through family health history with the theory of planned behavior: Prediction of type 2 diabetes risk factors and preventive behavior in an African American Population in Florida. Public Health Genomics, 19(2): 69-80. doi: 10.1159/000443471.

Thojampa S, Sarnkhaowkhom, C. (2019). The Social Cognitive Theory with Diabetes: Discussion. Int J Caring Sci, 12(2): 2. Retrieved from www.internationaljournalofcaringsciences.org.

WHO (2017). Country and regional data on diabetes. Retrieved from https://www.who.int/diabetes/facts/world_figures/en/index5.html.

Wongrith P (2019). Predicting diabetic selfcare management based on the theory of planned behavior among elderly with type 2 diabetes in Thailand. Diabetes Mellitus. 22(4): 367-376. doi: 10.14341/DM10290. 